\title{
El papel de la influencia interlingüística en el desarrollo de la competencia metafórica: estado de la cuestión y propuesta didáctica ${ }^{1}$
}

\author{
Julio Torres Soler ${ }^{2}$
}

Recibido: 24 de febrero de 2021 / Aceptado: 14 de julio de 2021

Resumen. Investigaciones recientes han demostrado que en el desarrollo de la competencia metafórica en una segunda lengua (L2) entra en juego, entre otros factores, la primera lengua (L1) del aprendiente. Ante esta evidencia, en el presente trabajo nos proponemos actualizar el tratamiento del lenguaje metafórico en el aula de segundas lenguas, incorporando una mayor atención al contraste entre la L1 y la L2. Para ello, en primer lugar, establecemos un estado de la cuestión en el que examinamos el impacto de la influencia interlingüística en el desarrollo de la competencia metafórica en una L2, con especial atención al papel de la L1 en las metodologías didácticas empleadas para la enseñanza de la metáfora. En segundo lugar, a modo de ilustración, nos centramos en el caso de la metáfora conceptual las emociones son sabores. Basándonos en un estudio previo en el que se analiza esta metáfora de forma contrastiva en español y en inglés, presentamos una propuesta didáctica original para estudiantes angloparlantes de español, en la que se aborda el lenguaje metafórico de los sabores.

Palabras clave: Metáfora conceptual; competencia metafórica; influencia interlingüística; transferencia; emociones.

[en] The role of cross-linguistic influence in the development of metaphoric competence: state of the art and teaching proposal

\begin{abstract}
Recent investigations have demonstrated that, among other factors, the learner's first language (L1) plays a role in the development of metaphoric competence in a second language (L2). In view of this evidence, in the present study, we attempt to update the treatment of metaphorical language in the second language classroom, by incorporating a greater attention to the contrast between the mother tongue and the target language. Therefore, first, a state of the field will be established, in which we examine the impact of cross-linguistic influence on the development of metaphoric competence in a L2, with special attention to the role of the L1 in the didactic methodologies that are employed to teach metaphors. Second, by way of illustration, we focus on the case of the conceptual metaphor emotions are tastes. Based on a previous work in which this conceptual metaphor is analyzed in Spanish and in English, we present an original didactic proposal for English-speaking students of Spanish, in which the metaphoric language of tastes is addressed.
\end{abstract}

Keywords: Conceptual metaphor; metaphoric competence; cross-linguistic influence; transfer; emotions.

[fr] Le rôle de l'influence interlinguistique dans le développement de la compétence métaphorique: état de l'art et proposition didactique

Résumé. Des recherches récentes ont montré que dans le développement de la compétence métaphorique dans une deuxième langue (L2), entre autres facteurs, la première langue (L1) de l'apprenant entrait en jeu. Compte tenu de cette évidence, dans le présent travail, nous proposons de mettre à jour le traitement du langage métaphorique dans la classe de deuxièmes langues, en intégrant une plus grande attention au contraste entre la L1 et la L2. Pour ce faire, tout d'abord, nous établissons un état de l'art dans lequel nous examinons l'impact de l'influence interlinguistique sur le développement de la compétence métaphorique en L2, avec une attention particulière au rôle de la L1 dans les méthodologies didactiques utilisées en l'enseignement de la métaphore. Deuxièmement, à titre d'illustration, nous nous concentrons sur le cas de la métaphore conceptuelle les émotions sont des saveurs. Sur la base d'une étude précédente dans laquelle cette métaphore est analysée de manière contrastive en espagnol et en anglais, nous présentons une proposition didactique originale pour les étudiants anglophones d'espagnol, dans laquelle la langue métaphorique des saveurs est abordée.

Mots-clés: Métaphore conceptuelle; compétence métaphorique; influence interlinguistique; transfert; émotions.

La presente investigación se fundamenta en un Trabajo Fin de Máster no publicado (Torres Soler, 2020), que ha sido posteriormente revisado y expandido para la elaboración de este artículo. Esta publicación ha sido posible gracias a la financiación del Ministerio de Universidades a través del programa de Formación del Profesorado Universitario (FPU2019-01505).

2 Departamento de Filología Española, Lingüística General y Teoría de la Literatura, Universidad de Alicante. julio.torres@ua.es 
Sumario: 1. Introducción. 2. Estado de la cuestión. 2.1. La competencia metafórica y su situación en la enseñanza de segundas lenguas. 2.2. Metáfora e influencia interlingüística. 2.3. Aspectos didácticos para la enseñanza de la metáfora. 3. La enseñanza de la metáfora conceptual las emociones son sabores. 3.1. Aspectos interlingüísticos de las emociones son sabores en español y en inglés. 3.2. Propuesta didáctica. 4. Conclusiones. 5. Bibliografía. 6. Anexo.

Cómo citar: Torres Soler, Julio (2021). El papel de la influencia interlingüística en el desarrollo de la competencia metafórica: estado de la cuestión y propuesta didáctica. Didáctica. Lengua y Literatura, 33, 145-156.

\section{INTRODUCCIÓN}

Hace 40 años que George Lakoff y Mark Johnson (1980), en su libro traducido al español como Metáforas de la vida cotidiana, pusieron de manifiesto que las metáforas, lejos de ser un recurso estético o literario, están presentes en gran medida en el lenguaje cotidiano. Los autores muestran que las metáforas tienen lugar en el sistema conceptual de las personas, es decir, que modelan la manera en que entendemos el mundo que nos rodea, mientras que el lenguaje metafórico es tan solo una de sus manifestaciones. A partir de la publicación de esta obra, el estudio de la metáfora pasa a ocupar un lugar destacado en la lingüística teórica, así como en otras ciencias cognitivas y sociales. Mucho más escasa es la atención que han recibido el aprendizaje y la enseñanza de la metáfora conceptual en segundas lenguas, aunque en los últimos años se ha producido un crecimiento sustancial de estudios sobre el tema (Hoang, 2014).

Un avance muy significativo en el ámbito la adquisición de la metáfora en segundas lenguas tiene que ver con el papel que desempeña la influencia interlingüística en el aprendizaje. Estudios recientes (Chen y Lai, 2014; Türker, 2015) muestran que las semejanzas en el lenguaje metafórico de la L1 y de la L2 tanto en el nivel conceptual como en el nivel de la expresión lingüística pueden facilitar el aprendizaje, mientras que las diferencias suponen una mayor dificultad para los aprendientes. Estos hallazgos apuntan a la necesidad de dedicar una atención explícita al contraste entre la L2 y la L1 de los estudiantes en el aula.

Ante estos descubrimientos, el presente trabajo pretende contribuir a mejorar el tratamiento del lenguaje metafórico en la enseñanza de segundas lenguas, con una atención particular al español como lengua extranjera (ELE). En el segundo apartado de este artículo, establecemos un estado de la cuestión en el que introducimos el concepto de competencia metafórica (\$2.1), revisamos el papel de la L1 en la adquisición del lenguaje metafórico en segundas lenguas (§2.2) y atendemos al rol de la L1 en las diferentes metodologías de la enseñanza del lenguaje metafórico (\$2.3). En el tercer apartado, mostramos cómo se puede llevar a cabo la enseñanza del lenguaje metafórico, centrándonos en el caso de la metáfora conceptual las emociones son sabores. Primero, revisamos algunas de las características de esta metáfora conceptual en español y en inglés (\$3.1) y, después, presentamos una secuencia de actividades original para estudiantes angloparlantes en la que se aborda el lenguaje metafórico de los sabores en español (§3.2), cuya plantilla se encuentra en el anexo.

\section{ESTADO DE LA CUESTIÓN}

\subsection{La competencia metafórica y su situación en la enseñanza de segundas lenguas}

El término competencia metafórica, acuñado por Marcel Danesi (1988), se refiere a la capacidad de comprender y producir metáforas eficazmente (Littlemore y Low, 2006, p. 269). Dado que la metáfora es un mecanismo del pensamiento, algunos autores como Danesi han situado la competencia metafórica en la más amplia competencia conceptual, que hace referencia a la capacidad de verbalizar los conceptos de forma que presenten una estructura conceptual adecuada a una determinada cultura (Danesi, 2003, p. 75). Por otro lado, Jeannette Littlemore y Graham Low (2006), basándose en el modelo de competencia comunicativa de Bachman (1990), han demostrado que la competencia metafórica influye de forma significativa en todas las áreas de la competencia comunicativa en una L2, lo implica que la enseñanza de la metáfora no debe restringirse a un único nivel del idioma, sino que debe llevarse a cabo teniendo en cuenta su naturaleza multidimensional. Aunque los investigadores se han centrado en diferentes aspectos de la competencia metafórica, todos ellos coinciden en reivindicar su importancia fundamental en todos los estadios del aprendizaje de una lengua extranjera y la necesidad de sistematizar su enseñanza.

Hace más de cuatro décadas, Danesi (1988) detectó que los hablantes de segundas lenguas utilizan un lenguaje mucho más literal que los hablantes nativos, hasta el punto de resultar "antinatural". A día de hoy, el lenguaje metafórico continúa estando en una situación de marginalidad en la enseñanza de segundas lenguas (Berdún Villamonte, 2021). Esta carencia se hace visible en los principales documentos de referencia para la enseñanza de lenguas. Gutiérrez Pérez (2017) muestra que el Marco Común Europeo de Referencia para las lenguas (MCER) (Consejo de Europa, 2002) presenta una visión anticuada de la metáfora que ignora su papel crucial en el sistema conceptual de los hablantes, puesto que, en la única alusión a la metáfora que se hace en el documento, se la clasifica como un tipo de "modismo", que a su vez se presentan como una clase de "expresiones hechas" (2002, p. 108). De forma similar, 
Masid Blanco (2015) explica que en el Plan Curricular del Instituto Cervantes (PCIC) (2006) el lenguaje metafórico está gravemente infrarrepresentado.

Por otro lado, algunos estudios sugieren que, cuando se introduce la metáfora conceptual en la enseñanza de segundas lenguas, en ocasiones no se hace de forma rigurosa. Skorczynska Sznajder (2010) realiza un estudio de corpus sobre el lenguaje metafórico que aparece en un manual de inglés para los negocios. El análisis del corpus revela que la selección de metáforas conceptuales y expresiones metafóricas del manual no refleja la realidad del lenguaje de los negocios, ya que buena parte de dichas metáforas conceptuales no resulta cuantitativamente relevante en el corpus, o bien las expresiones metafóricas del manual no responden al uso que realmente se hace de ellas. Por tanto, es necesario que la selección de las metáforas conceptuales y de las expresiones metafóricas se base en estudios de corpus que tengan en cuenta cuestiones como la frecuencia de las expresiones metafóricas y sus combinaciones.

\subsection{Metáfora e influencia interlingüística}

La utilización de elementos de la L1 (o de otras lenguas conocidas) en una L2 se ha denominado tradicionalmente transferencia, y más recientemente también influencia interlingüistica (Suárez Campos e Hijazo Gascón, 2019). Desde el punto de vista del producto, la influencia facilitadora de la L1 al transferir un elemento existente tanto en la L1 como en la L2 se denomina transferencia positiva, mientras que la comisión de errores producidos por la transferencia de elementos de la L1 que no existen en la L2 se ha denominado transferencia negativa. En lo que concierne al lenguaje metafórico, la influencia interlingüística puede darse en dos niveles: el nivel conceptual y el nivel de la expresión lingüística.

La idea de que puede existir una influencia interlingüística a nivel conceptual no es nueva. Kellerman (1995) ya defiende que los estudiantes deben aprender las diferencias en la forma que en que el mundo es conceptualizado en la L2. Jarvis (1998) desarrolla el concepto de transferencia conceptual, que no solo se refiere a la transferencia de la metáfora sino, en general, a cualquier tipo de influencia del conocimiento conceptual de la L1 sobre otras lenguas. En esta misma línea, Danesi (2008), desde el análisis de errores, utiliza el término error conceptual para referirse a las transferencias conceptuales negativas. Un ejemplo de error conceptual provocado por la transferencia negativa de una metáfora conceptual es el que detecta Danesi (2008, p. 242) en la expresión de un estudiante anglófono de italiano L2: "Anch'io sono sempre verde di gelosia" (lit.: también yo soy siempre verde de celos). El error está provocado por la transferencia desde la L1 (inglés) a la L2 (italiano) de la metáfora conceptual sentir envidia es ponerse de color verde (Ogarkova, 2007, p. 122), que es habitual en la lengua inglesa, pero no existe en italiano.

Por otro lado, puede darse el caso de que una metáfora conceptual existente en la L1 dé lugar a una transferencia positiva en la L2 a nivel conceptual, y sin embargo, la expresión metafórica transferida desde la L1 no exista en la L2, ocasionando, por lo tanto, una transferencia negativa de dicha expresión metafórica. Por ejemplo, Gómez Vicente (2019) detecta que la metáfora conceptual tristeza es oscuridad está presente tanto en francés como en español ("verlo todo negro"). Sin embargo, los aprendientes francófonos de español L2 utilizan algunas expresiones como "termina la noche con la cabeza llena de ideas negras", que pese a responder al esquema de la metáfora conceptual compartida por el francés y el español, resulta extraña, o al menos muy creativa, en español. Esto se debe a que la expresión metafórica "idées noires" (lit.: ideas negras) se utiliza de forma convencional para expresar pensamientos negativos en francés, por lo que se trata de una transferencia negativa de esta expresión a la lengua española.

Si bien la generalidad de los estudiosos de la metáfora advierte la necesidad de atender al contraste entre el sistema conceptual de la L1 y la L2 en la enseñanza de lenguas (véase §2.3), la importancia de la influencia interlingüística en el nivel de las expresiones metafóricas no siempre ha sido reconocida. Por ejemplo, Barcelona Sánchez (2001, p. 136), refiriéndose a las aplicaciones del análisis contrastivo del lenguaje metafórico, afirma que, si el objetivo del estudio es guiar la enseñanza de segundas lenguas, entonces el análisis contrastivo debe limitarse a comprobar la existencia de las metáforas en ambas lenguas, sin pararse a comprobar la presencia de expresiones metafóricas semejantes.

Sin embargo, numerosos estudios posteriores han revelado que tanto el conocimiento conceptual como lingüístico de la L1 los aprendientes puede ser transferido a la L2, influyendo significativamente el procesamiento del leguaje metafórico en la L2. Los trabajos de Charteris-Black (2002), Chen y Lai (2014) y Türker (2015) confirman la existencia de tres grados de dificultad en la comprensión de expresiones metafóricas en la L2, según su similitud con la L1. Las expresiones metafóricas más comprensibles son aquellas en las que tanto la expresión metafórica como la metáfora conceptual subyacente encuentran un correlato en la L1. Las expresiones metafóricas que responden a una metáfora conceptual existente en la L1, pero que no se expresan de forma semejante en la L1, presentan un grado mayor de dificultad. Por último, las expresiones metafóricas que ni se expresan de forma similar en la L1 ni responden a una metáfora conceptual existente en la L1 son las más difíciles de comprender, por lo que tienden a interpretarse en función del contexto (Chen y Lai, 2014, p. 329). Por su parte, el estudio de Zibin (2016) arroja resultados semejantes a las investigaciones anteriores, pero en este caso sobre la sobre la producción de expresiones metafóricas. En definitiva, estas recientes investigaciones permiten afirmar que tanto el conoci- 
miento conceptual como el lingüístico de los estudiantes en su L1 condicionan la comprensión y la producción de expresiones metafóricas en la L2.

\subsection{Aspectos didácticos para la enseñanza de la metáfora}

En este apartado, tratamos de ofrecer una visión amplia de las metodologías empleadas en la enseñanza de la metáfora. En primer lugar, nos centramos con especial atención en las metodologías que tienen en cuenta el contraste con la L1, para lo que revisamos algunas investigaciones de carácter empírico y ofrecemos una tipología de actividades. En segundo lugar, abordamos las metodologías que promueven el desarrollo de la conciencia metafórica, mostrando también un listado de posibles actividades. En último lugar, mostramos de forma más general otros tipos de actividades que suelen emplearse para la enseñanza de la metáfora y que afectan a dimensiones diversas de la competencia metafórica.

En términos generales, el uso del análisis contrastivo de L1 y la L2 en el aula de segundas lenguas ha sido ampliamente reivindicado, especialmente porque permite evitar transferencias negativas en cuestiones gramaticales, léxicas o semánticas (Galindo Merino, 2012). En menor medida, también se ha demostrado la conveniencia de utilizar pedagogías que fomenten la transferencia positiva, como los trabajos de Cummins (2008), quien desarrolla el concepto enseñar para la transferencia (teaching for transfer) y propone una serie de estrategias de utilización de la L1 para facilitar el aprendizaje de la L2, como enfocar el origen común de las palabras cognadas o utilizar diccionarios bilingües y multilingües (2008, p. 73). En el caso concreto de la enseñanza de la metáfora, los estudios que hemos revisado en el apartado anterior apuntan a la conveniencia de prestar una atención explícita no solo a la existencia de un mismo esquema metafórico en la L1 y en la L2, sino también en las diferencias que se encuentran en su expresión lingüística. Sin embargo, la investigación sobre las metodologías de aprendizaje que destacan el papel de la L1 en el desarrollo de la competencia metafórica es todavía escasa. Hasta ahora, los únicos estudios con los que contamos están basados en estudios de caso, en los que se lleva a cabo una única práctica docente innovadora y se realiza un análisis cualitativo de los resultados.

Entre estos estudios, podemos mencionar el de Villacañas de Castro (2018), quien lleva a cabo un taller de escritura poética en inglés como L2 con alumnos bilingües de español y catalán. En el taller, el autor aplica una pedagogía que trata de activar y promover la transferencia de la competencia metafórica de la L1 a la L2, basándose en la teoría de Cummins (2008), enseñar para la transferencia. Según el autor, los resultados muestran que la metodología empleada activó la transferencia de la competencia metafórica de la L1 a la L2. Por otro lado, resulta especialmente interesante el trabajo de Velasco-Sacristán (2009), quien enseña las metáforas del inglés de los negocios a estudiantes españoles aplicando una metodología basada en la traducción. El análisis cualitativo de los resultados de su experimento sugiere que el método empleado fue efectivo. Sin embargo, en ambas investigaciones, la ausencia de un grupo de control impide que las conclusiones a las que llegan los autores sean firmes. Por tanto, consideramos que es necesario desarrollar investigaciones experimentales que aporten mayor evidencia sobre los beneficios de utilizar metodologías que tengan en cuenta el papel de la L1 para la enseñanza de la metáfora.

Pese a la ausencia de estudios experimentales, la mayoría de especialistas están de acuerdo en que es necesario prestar atención a la L1 en la enseñanza de la metáfora y, para ello, proponen diferentes actividades. En la mayor parte de propuestas, las comparaciones entre la L1 y la L2 se limitan a comprobar la existencia o no de los mismos esquemas conceptuales, desatendiendo las semejanzas y diferencias que pueda haber en el nivel de la expresión lingüística. Las actividades que comparan las expresiones metafóricas de la L1 y la L2 tan solo a nivel conceptual son las siguientes:

- Actividades de reflexión. Es muy habitual que en las secuencias de actividades se incluya alguna pregunta como “¿existen metáforas similares en tu lengua?”, que trata de introducir a una reflexión general sobre la existencia de esquemas metafóricos compartidos por la L1 y la L2 (Gómez Vicente, 2013; Cuberos Vicente, 2014; Masid Blanco, 2014; Gutiérrez Pérez, 2018).

- Actividades de relacionar. Varios autores (Deignan et al., 1997; Acquaroni Muñoz, 2008; Martín Gascón, en prensa) proponen a los estudiantes que unan las expresiones metafóricas en la L2 con expresiones metafóricas semejantes en su L1, con el objetivo de que tomen conciencia de que los esquemas metafóricos son a menudo compartidos por diferentes lenguas.

- Actividades de elección de la opción correcta. Kaitian (2011) propone elegir entre la expresión metafórica correcta y otra expresión metafórica incorrecta en la que hay una transferencia conceptual negativa desde la L1 de los estudiantes.

Unos pocos autores también plantean actividades que dedican una atención explícita a la comparación de los aspectos lingüísticos de las expresiones metafóricas en la L1 y en la L2. Encontramos los siguientes tipos de actividades:

- Instrucción magistral. Zibin (2016) sugiere que, en los casos en los que una metáfora conceptual esté presente en la L1 y en la L2, el profesor puede escribir en la pizarra las expresiones metafóricas en la L1 al lado de las 
correspondientes expresiones en la L2, para que los estudiantes se percaten de las diferencias en su expresión lingüística.

- Actividades de traducción. Además de Velasco-Sacristán (2009), cuyo importante trabajo establece las directrices para el empleo de esta metodología, otros autores han incluido ejercicios de traducción para la enseñanza del lenguaje metafórico (Gutiérrez Pérez, 2017; Gómez Vicente, 2018). Con este tipo de actividades se logra concentrar la atención de los estudiantes tanto en aspectos conceptuales como en aspectos lingüísticos de las expresiones metafóricas en diferentes contextos discursivos.

En definitiva, hemos comprobado que las metodologías didácticas que atienden a la L1 en el desarrollo de la competencia metafórica requieren más investigación. Además, hemos mostrado la necesidad de prestar especial atención a aquellas metodologías que fomentan el contraste de las características lingüísticas de los enunciados metafóricos en la L1 y la L2, debido a la escasez de actividades de este tipo. Por este motivo, en nuestra propuesta didáctica (véase $\S 3.2$ ), incluimos un nuevo tipo de actividad que se basa en la detección del enunciado incorrecto, que no solo contiene transferencias conceptuales negativas de la L1, como ya propone Kaitian (2011), sino también transferencias lingüísticas negativas.

Otros aspectos metodológicos relacionados con la enseñanza de la metáfora han recibido mucha más atención por parte de los investigadores. Numerosos estudios experimentales (Boers, 2000, 2001) demuestran los beneficios de fomentar la conciencia metafórica (metaphorical awareness) de los estudiantes, es decir, su conocimiento de que el significado de las expresiones metafóricas no es arbitrario, sino motivado, así como el reconocimiento de las diferencias culturales y lingüísticas que afectan a las expresiones metafóricas. Los experimentos de Boers, así como algunos estudios realizados en el ámbito de la enseñanza de ELE (Acquaroni Muñoz, 2008; Masid Blanco, 2015), revelan que focalizar la atención de los estudiantes en la naturaleza metafórica de las expresiones favorece tanto la comprensión como la producción de las expresiones metafóricas. La conciencia metafórica puede fomentarse mediante diversos tipos de actividades, que presentamos a continuación:

- Actividades de detección. En estos ejercicios, los que los estudiantes deben detectar las expresiones metafóricas de un texto (Masid Blanco, 2014; Rivera León, 2016).

- Actividades de relacionar con la metáfora conceptual. Este tipo de actividades presentan expresiones metafóricas, preferiblemente contextualizadas, que el alumno debe vincular con la metáfora conceptual subyacente. Se trata del tipo de actividad más habitual en las propuestas didácticas que hemos revisado (Boers, 2001; Acquaroni Muñoz, 2008; Kaitian, 2011; Hijazo-Gascón, 2011; Gómez Vicente, 2013; Cuberos Vicente, 2014; Rivera León, 2016; Martín Gascón, 2020).

- Actividades de relacionar con imágenes. Varios autores plantean ejercicios en los que los alumnos deben relacionar las expresiones metafóricas con imágenes que representan gráficamente los significados literales correspondientes (Hijazo-Gascón, 2011; Cuberos Vicente, 2014; Gutiérrez Pérez, 2018; Altakhaineh y Shahzad, 2020). Es particularmente interesante la propuesta de Martín Gascón (en prensa) quien, en vez de imágenes, utiliza GIFs animados, un formato muy atractivo que consiste en una secuencia de imágenes que se repite en breves intervalos.

- Actividades basadas en la actuación. En este tipo de actividades, los estudiantes deben representar los significados literales de determinadas expresiones metafóricas mediante mímica. Lindstromberg y Boers (2005) y Saaty (2019) comprueban empíricamente los beneficios de poner en acción los significados literales de determinadas expresiones metafóricas y denominan a esta metodología enfoque basado en la actuación. En el ámbito de ELE, Cuberos Vicente (2014) también propone una actividad de mímica.

Como hemos visto, existe un gran consenso científico sobre la importancia de fomentar la conciencia metafórica, por lo que los expertos han propuesto actividades muy diversas para ello. Con este mismo objetivo, en nuestra propuesta didáctica presentamos un nuevo tipo de ejercicio que hemos denominado actividad basada en la experimentación (véase §3.2), que podría ser especialmente útil para la enseñanza de metáforas con vocabulario sensorial como dominio fuente.

Por último, ofrecemos un listado con otros tipos de actividades variadas que aparecen frecuentemente en las secuencias didácticas de los expertos:

- Actividades de rellenar huecos. En estas actividades, los estudiantes deben completar los enunciados con una serie expresiones metafóricas (Hijazo-Gascón, 2011; Masid Blanco, 2014; Gutiérrez Pérez, 2017).

- Actividades de consulta en diccionarios. Es habitual que se pida a los estudiantes que busquen en diccionarios los significados literales y metafóricos de determinadas unidades léxicas (Deignan et al., 1997; Lantolv y Bobrova, 2014; Gutiérrez Pérez, 2017).

- Actividades de elección entre sinónimos. En este tipo de actividades, con las que se persigue centrar la atención en el léxico, los estudiantes deben completar las expresiones metafóricas eligiendo entre dos unidades léxicas cuyos significados literales son sinónimos, siendo solo una de las dos palabras correcta en la expresión metafórica (Zibin, 2016; Gutiérrez Pérez, 2017). 
- Actividades de producción libre. En estas actividades, los estudiantes deben producir textos de forma contextualizada utilizando algunas de las metáforas aprendidas (Hijazo-Gascón, 2011; Masid Blanco, 2014; Rivera León, 2016).

De estos últimos tipos de actividades, en nuestra propuesta didáctica incluimos un ejercicio de producción libre, que es similar a los que se recogen en otras secuencias de actividades (véase §3.2).

\section{LA ENSEÑANZA DE LA METÁFORA CONCEPTUAL LAS EMOCIONES SON SABORES}

En la parte restante de este artículo, abordamos la enseñanza de la metáfora conceptual las emociones son sabores y de su expresión lingüística en español, centrándonos en las necesidades específicas de los estudiantes angloparlantes. Como se ha expuesto en el apartado 2.1., es fundamental que la enseñanza del lenguaje metafórico se apoye en estudios de corpus. Además, dada la importancia que la L1 tiene en el desarrollo de la competencia metafórica, es conveniente que se utilicen estudios contrastivos que muestren las semejanzas y diferencias de las expresiones metafóricas en la L1 y en la L2. Por estos motivos, nuestra propuesta didáctica se fundamentó en un análisis contrastivo basado en corpus lingüísticos de la metáfora emociones son sabores en español y en inglés. Más concretamente, se analizaron de forma cuantitativa y cualitativa 500 ocurrencias de adjetivos descriptores del sabor en inglés, extraídas del Corpus of Contemporary American English (COCA), y 600 ocurrencias comparables en español, extraídas del Corpus del Español del Siglo XXI (CORPES XXI). Aunque dicho análisis se presenta detalladamente en otro trabajo (Torres Soler, 2021), a continuación señalamos algunas de las semejanzas y diferencias que se encontraron, puesto que resultan relevantes para nuestra propuesta didáctica.

\subsection{Aspectos interlingüísticos de las emociones son sabores en español y en inglés}

En primer lugar, hemos de mencionar que las emociones son sabores es una metáfora conceptual de nivel genérico que puede encontrarse presumiblemente en numerosas lenguas del mundo, incluidas la española y la inglesa. Esta correspondencia se concreta en diferentes metáforas de nivel específico, que son, en su mayor parte, compartidas por los hablantes de español y de inglés, como es el caso de el agrado es sabor dulce, el desagrado es sabor agrio, la excitación es sabor picante, la aflicción es sabor amargo, la mezcla de agrado y disgusto es sabor agridulce y el aburrimiento es ausencia de sabor.

Sin embargo, en cada lengua el sabor salado da lugar a una metáfora conceptual diferente. En español contamos con la metáfora la hilaridad es sabor salado, mientras que en inglés se encuentra el enfado es sabor salado. Además, se identifica una cierta variación a nivel conceptual en la metáfora la aflicción es sabor amargo en español y en inglés, ya que en español solo conceptualizamos la tristeza en términos de sabor amargo, mientras que, en inglés, el rango del dominio meta parece ser mayor, dado que también permite conceptualizar sentimientos como el resentimiento o incluso la rabia, siempre que estén asociados a un profundo dolor emocional, como se aprecia en la frecuente expresión "bitter revenge" (lit.: "venganza amarga').

En el nivel lingüístico, podemos observar que las metáforas conceptuales que comparten el español y el inglés se expresan a través de diferentes variantes y elaboraciones más específicas, que en muchos casos coinciden en ambas lenguas, como en el caso de una persona agradable es dulce. Sin embargo, algunas correspondencias de este tipo solo se encuentran una de las dos lenguas, lo que podría causar dificultades a los estudiantes. Algunas de estas variantes específicas exclusivas del español son una película excitante es picante, una crítica mordaz es ácida, una película mordaz es ácida, un toro manso en el ruedo es soso. Igualmente, encontramos algunas correspondencias específicas que solo se encuentran en inglés, como el frío extremo es amargo y una economía en recesión es ácida.

Por último, encontramos diferencias que tienen que ver con las colocaciones léxicas o con las características gramaticales de las expresiones metafóricas, que podrían llevar a los estudiantes a equivocarse. Por ejemplo, respecto a la metáfora conceptual el agrado es dulce, en inglés el adjetivo sweet se combina frecuentemente con apelativos o nombres de persona expresiones vocativas, como "sweet heart" (lit.: 'dulce corazón'), mientras que en español estas colocaciones resultan extrañas. Respecto a la metáfora conceptual el desagrado es sabor ácido, resultan extremadamente frecuentes en inglés las colocaciones turn sour (lit.: ‘volverse ácido') y go sour (lit.: ‘ir ácido'), que expresan el empeoramiento de un proyecto o una situación, mientras que en español no encontramos expresiones similares. En cambio, en español son muy abundantes las expresiones metafóricas “dejar un sabor agridulce (en la boca)" y "dejar un sabor amargo (en la boca)", que no se documentan en inglés. Por último, llama la atención que, tanto en inglés como en español, la metáfora la aflicción es sabor amargo se combina con la metáfora tragar es aceptar, pero da lugar a dos expresiones diferentes: en español diríamos "un trago amargo" y en inglés "a bitter pill to swallow" (lit.: 'una pastilla amarga para tragar').

\subsection{Propuesta didáctica}

En esta sección, explicamos la metodología del diseño de nuestra propuesta didáctica, que incorpora algunos tipos de actividades novedosas que hemos creado inspirándonos en la evidencia de la investigación que hemos revisado en los 
apartados anteriores. La secuencia de actividades, titulada “¿A qué saben tus sentimientos?”, aborda las expresiones metafóricas de los sabores en español. En la tabla 1, se muestra la ficha técnica de la propuesta didáctica, mientras que en el anexo se ofrece la plantilla con las actividades.

Tabla 1. Ficha técnica de la propuesta didáctica “¿A qué saben tus sentimientos?” (Fuente: elaboración propia)

\begin{tabular}{|l|l|}
\hline \multicolumn{2}{|c|}{ ¿A qué saben tus sentimientos? } \\
\hline Nivel & B2. \\
\hline Destinatarios & Estudiantes anglófonos adolescentes o adultos. \\
\hline Duración & Una sesión y media (50 min. + 20 min.), 30 min. de trabajo en casa. \\
\hline Objetivos & $\begin{array}{l}\text { 1. Promover la conciencia metafórica implícitamente, reparando en la motivación de las metáforas de los sabo- } \\
\text { res a través de la experimentación. }\end{array}$ \\
$\begin{array}{l}\text { 2. Identificar semejanzas y diferencias entre las metáforas conceptuales de los sabores en la cultura de origen y } \\
\text { en la cultura meta. }\end{array}$ \\
$\begin{array}{l}\text { 3. Reconocer diferencias de uso de las expresiones metafóricas de los sabores en la L1 y en la L2. } \\
\text { 4. Producir un discurso de graduación en el que se expresen emociones, utilizando las expresiones metafóricas } \\
\text { de los sabores. }\end{array}$ \\
\hline Contenidos & $\begin{array}{l}\text { 1. Expresiones metafóricas de las unidades léxicas dulce, salado, amargo, agrio, ácido, picante, soso y agridulce. } \\
\text { 2. La expresión de las emociones en un discurso de graduación. }\end{array}$ \\
\hline Dinámicas & Individual, en parejas, en grupos. \\
\hline Materiales & Comprensión escrita, comprensión oral, expresión escrita, expresión oral, interacción oral. \\
\hline
\end{tabular}

La primera actividad de nuestra secuencia, a la que hemos llamado "Saborea", tiene como objetivo principal fomentar la conciencia metafórica de los estudiantes al dirigir su atención sobre la motivación experiencial de las metáforas conceptuales de los sabores. La metodología empleada en esta actividad está inspirada en los hallazgos de Lindstromberg y Boers (2005), quienes ponen de manifiesto que puede ser altamente beneficioso para los estudiantes tomar conciencia de la motivación de algunas metáforas conceptuales corporeizadas a través de la experimentación de los estímulos sensoriomotrices en los que se basan. Sin embargo, dado que las metáforas que abordamos tienen como dominio fuente un estímulo perceptivo y una acción corporal, creemos que es más adecuando denominar este tipo de ejercicio como actividad basada en la experimentación, y no actividad basada en la actuación, como es habitual referirse a las actividades de mímica.

La segunda actividad, titulada "Final de curso", tiene varias partes con diferentes objetivos complementarios. Por un lado, se pretende profundizar en el desarrollo de la conciencia metafórica, para lo que se proponen dos tareas diferentes que responden a dos de los tipos de actividades que hemos presentado anteriormente (véase §2.3). En primer lugar, mediante una detección, los estudiantes deben ser capaces de identificar las expresiones metafóricas de los sabores contextualizadas en un texto en español. En segundo lugar, mediante una actividad de relacionar con imágenes, tratamos de que los estudiantes interpreten el significado de las expresiones metafóricas gracias al contexto, tomando conciencia al mismo tiempo de las metáforas conceptuales que vinculan los sabores con las emociones en español. Por otro lado, se busca que los estudiantes se den cuenta de que todas las metáforas conceptuales que se han presentado existen también en su L1, a excepción de la hilaridad es sabor salado. Para ello, se propone una actividad de reflexión interlingüística. Además, a lo largo de esta actividad, se ha mostrado un modelo en español del género textual del discurso de graduación.

La tercera actividad, llamada "La expresión intrusa", ejemplifica un nuevo tipo de actividad para el contraste de las expresiones metafóricas en la L1 y la L2 a nivel conceptual y lingüístico, que se añade a los dos tipos mencionados anteriormente (véase §2.3). Más concretamente, esta actividad tiene por objetivo principal que los estudiantes reconozcan y comprendan las expresiones metafóricas de los sabores que son propias del español, diferenciándolas de aquellas en las que hay una influencia interlingüística negativa de su L1, principalmente en el nivel de expresión lingüística. En dos casos, la expresión "intrusa" contiene una transferencia conceptual negativa del inglés: "Antonio se pone muy salado cuando pierde, $[\ldots]$ " y "Vicente estaba muy amargo esos días, [...]". En otros dos casos, la expresión incorrecta incluye elaboraciones o correspondencias específicas que no existen en español, pero sí en la L1 de los estudiantes: "el viento amargo" y "la economía se volvió ácida". En otros casos, se incluyen expresiones inexistentes en español por sus características lingüísticas, pero que sí se encuentran de forma similar en inglés, como las que tienen que ver con los sabores dulce, agridulce y agrio, entre otras. Además, se ha intentado que los distractores contengan expresiones lingüísticas que sí existen en español, pero que no tienen un correlato en inglés, como por ejemplo "una ácida comedia" o "un amargo sabor en la boca". Gracias a la selección de los enunciados y a la guía del profesor, el estudiante puede percatarse de las características conceptuales y lingüísticas de las expresiones metafóricas que podrían resultar más problemáticas, debido a la influencia interlingüística de su L1.

La elección de los alimentos puede variar en función de la disponibilidad. Una opción sencilla sería cortar rodajas de pan y agregar condimentos representativos de cada sabor (azúcar, sal, tabasco...). 
Por último, la cuarta actividad, titulada "Exprésate", consiste en un ejercicio de producción libre, en la que los aprendientes deben redactar y leer en voz alta un discurso de final de curso, en el que expresen sus emociones hacia sus compañeros y hacia las experiencias vividas durante las clases. Se pide, además, que incluyan en sus discursos expresiones metafóricas con cinco sabores distintos.

\section{CONCLUSIONES}

Este trabajo es una modesta contribución a la mejora del tratamiento del lenguaje metafórico en el aula de segundas lenguas. En primer lugar, a través de la revisión de varios estudios previos, hemos aclarado el concepto de competencia metafórica y hemos mostrado que la atención que recibe en la enseñanza de idiomas sigue siendo todavía demasiado escasa. A continuación, hemos visto que los hablantes de segundas lenguas pueden transferir el conocimiento conceptual y lingüístico de su L1 para comprender y producir expresiones metafóricas en la L2. Por este motivo, hemos argumentado que en la enseñanza de segundas lenguas es necesario atender no solo a las diferencias y semejanzas que existen a nivel conceptual entre las lenguas, sino también a las que tienen que ver con la expresión lingüística de las metáforas. En la última parte de nuestro estado de la cuestión, se han revisado los diversos tipos de actividades que actualmente se emplean para la enseñanza de la metáfora, comprobando que pocos especialistas tienen en cuenta el contraste entre la L1 y la L2 tanto a nivel conceptual como lingüístico.

Una vez establecido el estado de la cuestión, nuestra aportación ha tomado como caso ilustrativo la metáfora conceptual las emociones son sabores. A través de una propuesta didáctica original, hemos incorporado algunos tipos de actividades, con las que tratamos de ampliar las herramientas metodológicas de las que actualmente disponen los docentes y creadores de contenidos. Una de ellas es una actividad basada en la experimentación de los estímulos gustativos que motivan las metáforas conceptuales en cuestión. Otra de ellas (y la más importante para los objetivos de nuestro trabajo) es una actividad de elección de enunciado intruso que, a partir de los datos de un análisis contrastivo español-inglés, ha sido diseñada con el objetivo de concentrar la atención del estudiante angloparlante sobre las diferencias y similitudes conceptuales y lingüísticas de su L1 y su L2.

En definitiva, pese a los importantes avances que se han producido en las últimas décadas, hemos mostrado que el conocimiento sobre la competencia metafórica en la enseñanza de segundas lenguas está en fase de desarrollo. Es necesario que en los próximos años se publiquen más estudios que, basándose en los hallazgos sobre la adquisición de la metáfora, aborden la eficacia de las diferentes metodologías didácticas y propongan estrategias pedagógicas innovadoras para el desarrollo de la competencia metafórica. Desde nuestro punto de vista, sería particularmente interesante que en el futuro se llevasen a cabo investigaciones experimentales que comparasen la eficacia de las actividades que atienden al contraste de la L1 y la L2 con las que no tienen en cuenta la L1 de los estudiantes.

\section{BIBLIOGRAFÍA}

Acquaroni Muñoz, Rosana (2008). La incorporación de la competencia metafórica (CM) a la enseñanza-aprendizaje del español como segunda lengua (L2) a través de un taller de escritura creativa: estudio experimental [Tesis doctoral, Universidad Complutense de Madrid].

Altakhaineh, Abdel Rahman Mitib y Nimra M. Shahzad (2020). Using pictures in teaching metaphorical expressions to Arabic-speaking EFL learners. The Asian Journal of Applied Linguistics, 7(1), 32-44.

Bachman, Lyle. F. (1990). Fundamental Considerations in Language Testing. Oxford: Oxford University Press.

Barcelona Sánchez, Antonio (2001). On the systematic contrastive analysis of conceptual metaphors: Case studies and proposed methodology. En Martin Pütz, Susanne Niemeier y Rene Dirven (eds.). Applied Cognitive Linguistics II: Language Pedagogy (pp. 117-146). Berlin: De Gruyter.

Berdún Villamonte, Irune (2021). La presencia de las expresiones metafóricas en ocho manuales de ELE de nivel B1. MarcoELE. Revista de Didáctica Español Lengua Extranjera, 32(1).

Boers, Frank (2000). Metaphor awareness and vocabulary retention. Applied Linguistics, 21(4), 553-571.

Boers, Frank (2001). Remembering figurative idioms by hypothesising about their origin. Prospect, 16(3), 35-43.

Charteris-Black, Jonathan (2002). Second language figurative proficiency: A comparative study of Malay and English. Applied Linguistics, 23(1), 104-133.

Chen, Yi-Chen y Huei-ling Lai (2014). The influence of cultural universality and specificity on EFL learners' comprehension of metaphor and metonymy. International Journal of Applied Linguistics, 24(3), 312-336.

Consejo de Europa (2002). Marco común europeo de referencia para las lenguas: aprendizaje, enseñanza, evaluación. Ministerio de Educación, Cultura y Deporte.

Cuberos Vicente, Rocío (2014). El enfoque léxico y la competencia metafórica: Una propuesta didáctica [Trabajo final de máster, Universitat de Barcelona y Universitat Pompeu Fabra]. 
Cummins, Jim (2008). Teaching for transfer: Challenging the two solitudes assumption in bilingual education. En Nancy Hornberger (ed.). Encyclopedia of Language and Education (vol. 5) (pp. 65-75). Berlín: Springer.

Danesi, Marcel (1988). The development of metaphorical competence: A neglected dimension in second language pedagogy. En Albert N. Mancini, Paolo Giordano y Pier Rai Baldini (eds.). Selected Papers from the Proceedings of the Third Annual Conference of the American Association of Teachers of Italian (pp. 1-10). River Forest, IL: Rosary College.

Danesi, Marcel (2003). Second Language Teaching. A View from the Right Side of the Brain. Dordrecht: Kluwer Academy Publishers.

Danesi, Marcel (2008). Conceptual errors in second-language learning. En S. De Knop y T. De Rycker (eds.). Cognitive Approaches to Pedagogical Grammar: A Volume in Honour of René Dirven (pp. 231-256). Berlin: Mouton de Gruyter.

Deignan, Alice, Danuta Gabryś-Barker y Agnieszka Solska (1997). Teaching English metaphors using cross-linguistic awareness-raising activities. ELT Journal, 51(4), 352-360.

Galindo Merino, María del Mar (2012). La lengua materna en el aula de ELE. Asociación para la Enseñanza del Español como Lengua Extranjera (ASELE).

Gómez Vicente, Lucía (2013). L'expression métaphorique de l'évènement émotionnel en français (L1) et en espagnol (L1/L2): les images schéma haut/bas et dedans/dehors. Analyse descriptive et proposition didactique. Recherches en Didactique des Langues et des Cultures, 10(1), 81-102.

Gómez Vicente, Lucía (2018). Enseñanza del léxico de especialidad a través de la metáfora conceptual: Protocolo didáctico. En Aura Luz Duffé Montalvan (ed.). Estudios sobre el léxico. Puntos y contrapuntos (pp. 365-394). Berna: Peter Lang.

Gómez Vicente, Lucía (2019). La expresión de las emociones en la enseñanza del español LE/L2. En Iraide IbarretxeAntuñano, Teresa Cadierno López y Alejandro Castañeda Castro (eds.). Lingüística cognitiva y español LE/L2 (pp. 340-370). Londres: Rouletdge.

Gutiérrez Pérez, Regina (2017). Teaching Conceptual Metaphors to EFL Learners in the European Space of Higher Education. European Journal of Applied Linguistics, 5(1), 87-114.

Gutiérrez Pérez, Regina (2018). The development of a metaphoric competence. A didactic proposal of educational innovation. Innovation in Language Learning and Teaching, 13(3), 1-27.

Hijazo-Gascón, Alberto (2011). Las metáforas conceptuales como estrategias comunicativas y de aprendizaje: Una aplicación didáctica de la lingüística cognitive. Hispania, 94(1), 142-154.

Hoang, Ha (2014). Metaphor and Second Language Learning: The State of the Field. TESL-EJ, 18(2), 1-27.

Instituto Cervantes (2006). El plan curricular del Instituto Cervantes: niveles de referencia para el español. Madrid: Edelsa.

Jarvis, Scott (1998). Conceptual Transfer in the Interlingual Lexicon. Bloomington, IN: IULC.

Kaitian, Lu (2011). Metáforas en la enseñanza del español a alumnos chinos: propuestas didácticas para mejorar la conciencia y competencia metafórica. En N. Arriaga Arrelo, R. Blasco García, A. M. Ducasse, S. González FernándezCorugedo, A. Mateo Pérez, F. J. Menéndez Sánchez, A. J. Sánchez Griñán, J. Robisco García y M. J. Blanco (eds.). Artículos del II Congreso de Español como Lengua Extranjera en Asia-Pacífico (pp. 329-346). Manila: Centro Virtual Cervantes.

Kellerman, Eric (2000). Lo que la fruta puede decirnos acerca de la transferencia léxico-semántica: una dimensión no estructural de las percepciones que tiene el aprendiz sobre las relaciones lingüísticas. En Carmen Muñoz (ed.). Segundas lenguas: adquisición en el aula (pp. 21-379). Barcelona: Ariel.

Lakoff, George y Mark Johnson (1980). Metaphors we live by. Chicago: University of Chicago Press.

Lantolf, James P. y Larysa Bobrova (2014). Metaphor instruction in the L2 Spanish classroom: Theoretical argument and pedagogical program. Journal of Spanish Language Teaching, 1(1), 46-61.

Lindstromberg, Seth y Frank Boers (2005). From movement to metaphor with manner-of-movement verbs. Applied Linguistics, 26(2), 241-261.

Littlemore, Jeannette, y Graham Low (2006). Metaphoric competence, second language learning, and communicative language ability. Applied Linguistics, 27(2), 268-294.

Martín Gascón, Beatriz (2020). Potenciando la competencia metafórica en tiempos de COVID: Flippear la clase de ELE con Microsoft Teams. En Conference Proceedings EDUNOVATIC 2020 (pp. 620-623). Madrid: Redine.

Martín Gascón, Beatriz (en prensa). Engaging ELE learners: Emotion metaphors on GIFs. Education, Innovation and Training for Sustainable Development in the Context of COVID-19. Madrid: Dykinson.

Masid Blanco, Ocarina (2014). La metáfora lingüística en el aula de ELE. En Narciso Miguel Contreras Izquierdo (ed.). La enseñanza del Español como LE/L2 en el siglo XXI (pp. 893-902). Asociación para la Enseñanza del Español como Lengua Extranjera.

Masid Blanco, Ocarina (2015). La metáfora lingüística en el desarrollo de la competencia léxica en ELE: propuesta semántica y didáctica sobre el léxico somático desde un punto de vista cognitivo [Tesis doctoral, Universidad Complutense de Madrid].

Ogarkova, Anna (2007). Green-eyed monsters: a corpus-based study of the concepts of Envy and Jealousy in modern English". Metaphorik.de, 13, 87-147. 
Rivera León, Lorena (2016). La metáfora como recurso didáctico en el aula de ELE: un estudio a partir de la lingüística cognitiva. Boletín de la Asociación para la Enseñanza del Español como Lengua Extranjera, 54, 13-25.

Saaty, Rawan A. (2019). An Enactment-Based Approach to the Teaching of Metaphoric Expressions: A Case of Saudi EFL Learners. En Ana María Piquer Píriz y Rafael Alejo González (eds.). Metaphor in Foreign Language Instruction (pp. 263-285). Berlín: De Gruyter.

Skorczynska Sznajder, Hanna (2010). A corpus-based evaluation of metaphors in a business English textbook. English for Specific Purposes, 29(1), 30-42.

Suárez Campos, Laura y Alberto Hijazo Gascón (2019). La metáfora conceptual y su aplicación a la enseñanza de español LE/L2. En Iraide Ibarretxe-Antuñano, Teresa Cadierno López y Alejandro Castañeda Castro (eds.). Lingüística cognitiva y español LE/L2 (pp. 235-252). Londres: Rouletdge.

Torres Soler, Julio (2020). La diversidad del lenguaje metafórico: un estudio picante de las metáforas de los sabores en español y en inglés y su aplicación a la enseñanza de ELE [Trabajo fin de máster no publicado, Universidad de Alicante].

Torres Soler, Julio (2021). Variation in embodied metaphors: a contrastive analysis of taste metaphors in Spanish and English [Manuscrito presentado para su publicación].

Türker, Ebru (2015). The role of L1 conceptual and linguistic knowledge and frequency in the acquisition of L2 metaphorical expressions. Second Language Research, 32(1), 25-48.

Velasco-Sacristán, Marisol (2009). A translation approach to metaphor teaching in the LSP classroom: Sample exercises from a Business English School. Ibérica: Revista de la Asociación Europea de Lenguas para Fines Especificos, 17, 83-98.

Villacañas de Castro, Luis. S. (2018). Una exploración de la transferencia interlingüística de la competencia metafórica en estudiantes bilingües (español/catalán) de inglés como lengua extranjera: un caso de estudio. Tejuelo: Didáctica de la Lengua y la Literatura. Educación, 27, 119-148.

Zibin, Aseel (2016). On the production of metaphors and metonymies by Jordanian EFL learners: acquisition and implications. Topics in Linguistics, 17(2), 41-58.

\section{ANEXO}

\section{A. Saborea}

A.1. Te proponemos que, con los ojos cerrados, pruebes una serie de alimentos que el profesor o la profesora te va a proporcionar. Cuando pruebes un alimento, debes asociar su sabor con una persona, con un lugar y con una vivencia personal que te hayan hecho sentir de forma similar, y a continuación, puedes escribirlos en un folio.

A.2. ¿Qué tienen entre sí en común la persona, el lugar y la vivencia personal que has asociado a cada alimento? Comenta con tus respuestas con un compañero o compañera y explica por qué has relacionado dichos elementos con el alimento correspondiente.

\section{B. Final de curso}

B.1. Carlos va a dar el discurso de graduación del máster que ha cursado este año. Su discurso está lleno de adjetivos que indican sabores, pero que en este caso no se refieren a la comida. Lee el texto con atención y subraya los sabores que encuentres.

Queridos compañeros y compañeras:

Hoy damos por finalizado el curso de español y he de decir que tengo una sensación agridulce. Durante este tiempo, he disfrutado de poder trabajar con personas maravillosas, como Lupe, una chica muy salada que siempre anda haciendo bromas, o como Anna, que con su humor ácido expresa lo que muchos piensan, pero no se atreven a decir. Sin ellas y sin el resto de compañeros, la universidad sería un lugar soso y excesivamente serio. Tener que despedirme de vosotros me deja un sabor amargo en la boca.

Quiero aprovechar este discurso para felicitar a Katia, porque el nacimiento de su bebé, Alicia, ha sido una de las mejores noticias que hemos recibido este año. Todavía recuerdo cómo los rumores picantes sobre su posible embarazo se confirmaron un lunes por la noche, entre aplausos y lágrimas de emoción, en el edificio polivalente. Como este, me llevo muchos recuerdos dulces del máster y de todos los que formáis parte, aunque el final del curso haya estado marcado por un agrio confinamiento que nadie podía prever. Os deseo un futuro estupendo tanto en lo personal como en lo profesional. Muchas gracias.

B.2. A continuación, a partir del significado que tienen en el discurso, asocia cada uno de los sabores que has subrayado con uno de los siguientes emoticonos, que indican una emoción. Hay una excepción: los sabores ácido y agrio expresan la misma emoción. 


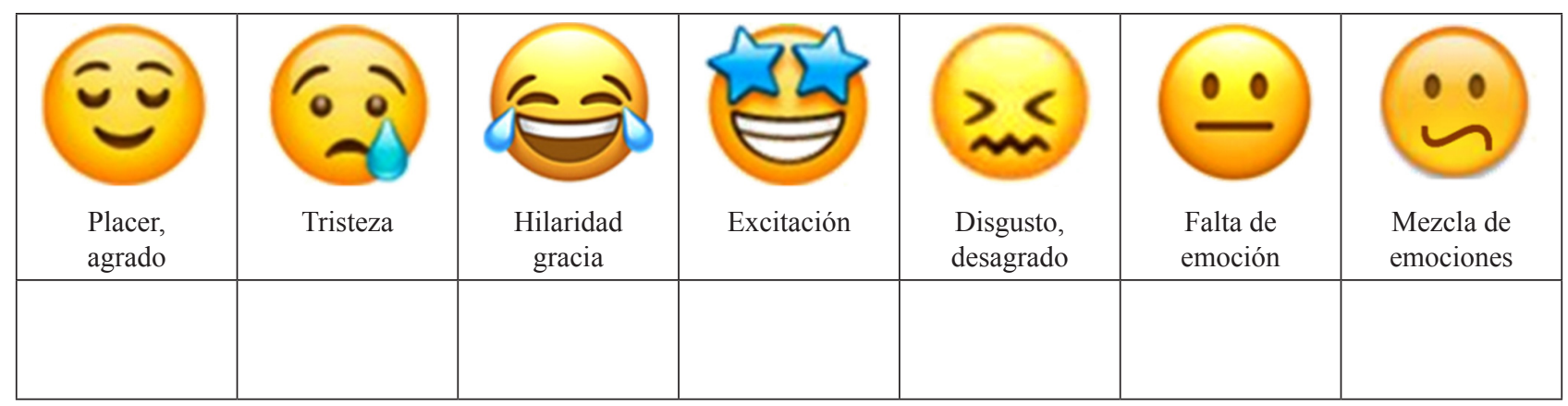

B.3. Piensa en los elementos que habías escrito en la actividad 1 y en las emociones que has asignado a cada sabor en el apartado anterior. ¿Se asocian los sabores a las mismas emociones en tu lengua materna? ¿Qué similitudes y diferencias encuentras?

\section{La expresión intrusa}

Ahora que ya sabes con qué emociones pueden expresar en español los sabores, vamos a aprender a usarlos correctamente. Para ello, te presentamos una serie de enunciados en los que aparecen sabores expresando emociones. En cada grupo de tres enunciados, hay un "intruso", es decir, hay un enunciado que es extraño en español. Descubre cuál es.
a) Alicia tiene una sonrisa muy dulce que gusta a todo el mundo.
b) Roberto, nuestro vecino del quinto, es un anciano muy dulce.
c) Dulce corazón, ¿puedes pasarme la sal?
a) Alejandra es cantante y tiene una voz muy dulce.
b) Mamá, he aprobado el examen de conducir. - ¡Dulce!
c) Guardo un recuerdo muy dulce el día que la conocí.

a) Eva me ha caído genial, es muy salada.
b) Antonio se pone muy salado cuando pierde, ino se le puede decir nada!
c) El título suena muy salado en inglés, pero la traducción al español no consigue el mismo efecto.

a) Jorge se sentía muy picante, así que decidió salir de fiesta para ligar.

b) El artículo se hacía eco de la picante polémica causada por los comentarios de Piqué sobre la selección española de fútbol.

c) Las últimas películas de Woody Allen son especialmente picantes, por eso están clasificadas como películas para adultos.

a) En Alaska en invierno es imprescindible protegerse del viento amargo.

b) Sentí una amarga desilusión cuando me despidieron del trabajo.

c) Aquellas amargas palabras le hicieron llorar.

a) Vicente estaba muy amargo esos días, no podía contener la rabia que sentía.

b) Guardo un recuerdo amargo de aquellos días.

c) La derrota fue muy amarga.

a) Aquel suspenso fue una pastilla amarga para tragar.

b) Su salida de la casa me dejó un amargo sabor en la boca durante horas.

c) La muerte de su amigo fue un amargo trago.

a) Marta hizo una crítica ácida sobre la falta de honestidad de la clase política.

b) En el año 2020 la economía se volvió ácida debido a la crisis sanitaria.

c) Ocho apellidos vascos es una ácida comedia que retrata la rusticidad del País Vasco.

a) En el parlamento se vivió un agrio debate sobre la corrupción.

b) El hoyo es una agria película sobre la miseria moral del ser humano.

c) El proyecto de investigación se puso agrio por la falta de financiación.

a) Hoy me siento muy sosa, no tengo ganas de hacer nada.

b) La corrida de toros fue un fracaso porque los toros eran muy sosos.

c) David es un chico muy soso, nunca dice nada divertido ni interesante.

a) Mudarse a otro país suele ser una experiencia agridulce.

b) Sacar un cinco en el examen me dejó un sabor agridulce en la boca.

c) Juan tiene un carácter agridulce, porque no es del todo simpático, pero tampoco antipático. 


\section{Exprésate}

Escribe un emotivo discurso de graduación sobre el curso de español al que estás asistiendo. Para ello, debes utilizar al menos cinco sabores diferentes para expresar tus sentimientos sobre lo que has vivido, las personas que has conocido, lo que has aprendido, etc. Practica la pronunciación y léelo en voz alta a tus compañeros. 